Ciência Florestal, Santa Maria, v. 24, n. 4, p. 857-867, out.-dez., 2014

ISSN 0103-9954

\title{
CONSERVAÇÃO DA VIABILIDADE E VIGOR DE SEMENTES DE Araucaria angustifolia (Bertol.) Kuntze DURANTE O ARMAZENAMENTO
}

\author{
CONSERVATION OF THE VIABILITY AND VIGOR OF Araucaria angustifolia (Bertol.) Kuntze \\ SEEDS DURING THE STORAGE
}

Cristhyane Garcia ${ }^{1}$ Cileide Maria Medeiros Coelho ${ }^{2}$ Marcelo Maraschin ${ }^{3}$ Luciana Magda de Oliveira ${ }^{4}$

\section{RESUMO}

A conservação das sementes de araucária é amplamente comprometida em função das suas características recalcitrante, o que dificulta o planejamento de ações de recuperação das populações degradadas. Desta forma, objetivou-se com o trabalho monitorar as alterações fisiológicas em sementes de araucária, sob diferentes condições de armazenamento, visando obter subsídios para a conservação de sua viabilidade e vigor. Avaliou-se a qualidade fisiológica das sementes recém-colhidas e a cada 60 dias, ao longo do armazenamento em ambiente de laboratório sem controle térmico, em refrigerador $\left(5^{\circ} \mathrm{C}\right)$ e em freezer $\left(-18^{\circ} \mathrm{C}\right)$, até o período de 180 dias. Após cada período amostral, avaliou-se a viabilidade (teste de germinação e tetrazólio) e o vigor das sementes (envelhecimento artificial, índice de velocidade de germinação - IVG e condutividade elétrica). Observou-se redução na porcentagem de plântulas normais ao longo do período de armazenamento das sementes de araucária. A conservação em freezer e em ausência de controle térmico causou a perda total de viabilidade das sementes aos 60 e 180 dias de armazenamento, respectivamente. Já o armazenamento em refrigerador favoreceu a conservação da viabilidade das sementes, com $64 \%$ de germinação aos 180 dias de armazenamento, um evento associado à redução da atividade metabólica das sementes. Com base nos testes de viabilidade e vigor, conclui-se que o armazenamento em refrigerador proporcionou a conservação das sementes de araucária por tempo superior em comparação às demais condições de armazenamento.

Palavras-chave: araucária; conservação de sementes; potencial fisiológico; sementes recalcitrantes.

\begin{abstract}
The conservation of Araucaria seeds is widely compromised in function of their recalcitrant feature, which hampers the planning of recovery actions of the degraded populations. Therefore, the objective of this study was to monitor the physiological changes in Araucaria seeds under controlled storage conditions, in order to get insights as to the viability and vigor conservation. The physiological quality of freshly harvested seeds was evaluated and every 60 days throughout the 180 days-storage period in laboratory ambient without thermal control, refrigerator $\left(5^{\circ} \mathrm{C}\right)$, and freezer $\left(-18^{\circ} \mathrm{C}\right)$ until the final period of 180 days. After each sampling period, the seed viability (germination and tetrazolium tests) and vigor (artificial aging, germination speed index - IVG and electrical conductivity) were assessed. A reduction in the normal

1 Engenheira Florestal, Msc., Doutoranda em Recursos Genéticos Vegetais, Departamento de Fitotecnia, Centro de Ciências Agrárias, Universidade Federal de Santa Catarina, Rod. Admar Gonzaga, 1346, Itacorubi, CEP 88034001, Florianópolis (SC), Brasil. crisggargioni@hotmail.com

2 Engenheira Agrônoma, Dra., Professora do Departamento de Agronomia, Centro de Ciências Agroveterinárias, Universidade do Estado de Santa Catarina, Av. Luiz de Camões, 2090, Conta Dinheiro, CEP 88520-000, Lages (SC), Brasil. Orientadora no RGV-UFSC. cileide.coelho@pq.cnpq.br

3 Engenheiro Agrônomo, Dr., Professor do Departamento de Fitotecnia, Centro de Ciências Agrárias, Universidade Federal de Santa Catarina, Rod. Admar Gonzaga, 1346, Itacorubi, CEP 88034-001, Florianópolis (SC), Brasil. m2@cca.ufsc.br

4 Engenheira Florestal, Dra., Professora do Departamento de Engenharia Florestal, Centro de Ciências Agroveterinárias, Universidade do Estado de Santa Catarina, Av. Luiz de Camões, 2090, Conta Dinheiro, CEP 88520-000, Lages (SC), Brasil. luciana@cav.udesc.br
\end{abstract}

Recebido para publicação em 19/10/2011 e aceito em 8/05/2013 
seedlings percentage was noticed over the period of storage of Araucaria seeds. The conservation in freezer and the lack of thermal control caused a complete loss of the seed viability at 60 and 180 days of storage, respectively. However, the refrigerator storage promoted the conservation of seed viability, with $64 \%$ germination after 180 days of storage, an event associated with the reduction of the metabolic activity of seeds. Based on the viability and vigor tests, it was concluded that storage in refrigerator provided longer storage periods to Araucaria seeds in comparison to the other storage conditions herein studied.

Keywords: araucaria; seed conservation; physiological vigor; recalcitrant seeds.

\section{INTRODUÇÃO}

A araucária (Araucaria angustifolia (Bertol.) Kuntze) é o principal componente da Floresta Ombrófila Mista, porém, a progressiva extinção de suas populações, decorrentes de seu alto valor madeireiro, resinífero e alimentar (EIRA et al., 1994), levaram-na à inclusão na lista de espécies ameaçadas da International Union for Conservation of Nature and Natural Resources - IUCN como criticamente em perigo (FARJON, 2006). A espécie consta também na Lista Oficial das Espécies da Flora Brasileira Ameaçadas de Extinção (BRASIL, 2008).

A recomposição de áreas com araucária é dificultada pela baixa viabilidade de suas sementes, principal forma de propagação da espécie (RAMOS e CARNEIRO, 1988), que diminui gradativamente após a colheita (LORENZI, 2002), sendo a espécie caracterizada como recalcitrante (TOMPSETT, 1984). Devido a esta característica recalcitrante, as sementes de araucária podem perder totalmente a viabilidade em 120 dias (LORENZI, 2002) ou 180 dias (FOWLER et al., 1998) após a maturação. Outros autores chegaram a encontrar acima de 30\% de viabilidade após 190 dias de armazenamento em temperatura ambiente variando entre 15 e $25^{\circ} \mathrm{C}$ (FERREIRA e HANDRO, 1979), mas, mesmo assim, tal característica pode limitar os programas de restauração, os quais exigem grandes quantidades de sementes com boa qualidade fisiológica.

A máxima qualidade fisiológica, alcançada na fase de maturação das sementes, pode decrescer a partir deste ponto, dependendo dos fatores ambientais aos quais as sementes estão expostas. $\mathrm{O}$ armazenamento adequado das sementes pode ser uma alternativa para prolongar a sua qualidade fisiológica, diminuindo a velocidade de deterioração. Este fato gerou algumas pesquisas sobre o período de manutenção da viabilidade das sementes de araucária durante condições específicas de armazenamento. Alguns autores indicam que a qualidade das sementes da espécie pode ser mantida, com percentual de germinação de $97 \%$, se armazenadas sob condições de refrigeração entre 0 e $1^{\circ} \mathrm{C}$ por um período de até 180 dias (CAÇOLA et al., 2006). De outra forma, tem sido relatado que pode haver $61 \%$ de germinação de sementes de araucária armazenadas por período de até 360 dias em embalagem de polietileno semipermeável em câmara fria $\left(4 \pm 1^{\circ} \mathrm{C}\right.$ e $89 \pm 1 \%$ de umidade relativa) (FOWLER et al., 1998). No entanto, os estudos acima referidos não relatam, ou relatam outras características associadas ao vigor, e alguns não especificam claramente o critério utilizado para considerar as amostras como germinadas.

O que parece existir é um consenso quanto ao fato de que temperaturas próximas a $0^{\circ} \mathrm{C}$ seriam ideais à manutenção da capacidade germinativa de sementes de araucária (PIRIZ CARRILLO et al., 2003). De fato, o armazenamento de sementes da espécie em temperaturas superiores a $20^{\circ} \mathrm{C}$ causa perdas significativas de viabilidade devido ao gasto energético com a respiração e à desorganização celular associada à desidratação e à senescência dos tecidos (AMARANTE et al., 2007).

Uma das formas de avaliar o nível de deterioração da semente previamente ao tempo de armazenamento é por meio do teste de envelhecimento artificial, baseado no fato de que há aumento da deterioração das sementes expostas à elevada temperatura e umidade relativa do ar. Alguns autores observaram reduções nas porcentagens e índices de velocidade de emergência com o aumento do período de envelhecimento de sementes de araucária à temperatura de $43 \pm 2^{\circ} \mathrm{C}$ (RAMOS e CARNEIRO, 1991). Em outros casos, as sementes de araucária submetidas ao envelhecimento artificial à temperatura de $40^{\circ} \mathrm{C}$ atingiram a perda total de viabilidade após 9 dias de envelhecimento (FONTES et al., 2001).

Diante dos relatos de trabalhos na literatura, observa-se que ainda não há um método consistente para a manutenção da qualidade de sementes de araucária, visto que esta manutenção é altamente dependente das condições de armazenamento. 
Portanto, objetivou-se avaliar as alterações na viabilidade e no vigor em sementes de araucária durante o armazenamento controlado.

\section{MATERIAL E MÉTODO}

A araucária possui um grande diásporo, o pinhão, no qual está presente o embrião que contém dois cotilédones, e o tecido de reserva formado pelo endosperma primário ou gametófito (FERREIRA, 1981). Para a espécie, o diásporo tem sido considerado a semente com invólucros e, no decorrer deste trabalho, será utilizada a denominação "semente" para a unidade de dispersão, conforme recomendado por Ferreira e Handro (1979). Desta forma, utilizaram-se sementes maduras de araucária coletadas em uma população no município de Painel (275' de latitude sul, 5006' de longitude oeste e altitude média de 1144 metros), no planalto sul de Santa Catarina. As sementes, após separadas das pinhas, foram armazenadas em embalagens plásticas transparentes com espessura de $0,015 \mu \mathrm{m}$, em ambiente natural de laboratório sem controle térmico, em refrigerador $\left(5^{\circ} \mathrm{C}\right.$ e $45 \%$ de umidade relativa), ou em freezer $\left(-18^{\circ} \mathrm{C}\right.$ e $90 \%$ de umidade relativa). As sementes que foram armazenadas em ambiente natural de laboratório ficaram expostas à variação de temperatura de -3 a $30^{\circ} \mathrm{C}$ e de umidade relativa de 33 a $99 \%$ para o período de armazenamento das respectivas sementes, sendo que a temperatura e umidade relativa médias foram de $15^{\circ} \mathrm{C}$ e $80 \%$, respectivamente, entre os meses de julho e dezembro de 2010 (EPAGRI/CIRAM, 2011).

As sementes recém-colhidas e armazenadas nas condições anteriormente citadas foram avaliadas em intervalos de 60 dias, ao longo de um período amostral de 180 dias, quanto ao grau de umidade, germinação, envelhecimento artificial, índice de velocidade de germinação, condutividade elétrica e tetrazólio.

O grau de umidade das sementes foi determinado a partir de três repetições de três sementes cortadas transversalmente conforme recomendação de Ramos e Bianchetti (1990), as quais foram pesadas e levadas à estufa a $105^{\circ} \mathrm{C} \pm 3^{\circ} \mathrm{C}$, por 24 horas (BRASIL, 2009).

As sementes foram tratadas com solução de hipoclorito de sódio $(2 \%, v / v)$, por 3 minutos, previamente ao teste de germinação, o qual foi conduzido utilizando-se quatro repetições de 25 sementes/tratamento. Utilizaram-se bandejas plásticas com substrato areia, previamente esterilizada, a qual foi umedecida até cerca de $60 \%$ da capacidade máxima de retenção de água, conforme indicado nas Regras para Análise de Sementes - RAS (BRASIL, 2009), monitorando-se a quantidade de água durante o período de duração do teste. $\mathrm{O}$ teste foi realizado em câmara germinativa BOD, com luminosidade constante e temperatura de $25^{\circ} \mathrm{C}$. As avaliações de percentual de plântulas normais ocorreram aos 14, 28, 42, 56 e 70 dias após a instalação do teste. Padronizou-se a avaliação aos 70 dias após o início do teste de germinação para comparação dos efeitos dos tratamentos, por este ser o tempo no qual as sementes expressaram seu máximo potencial germinativo, i.e., alta taxa de germinação das sementes recém-colhidas $(90 \%)$. Período semelhante (60 dias após instalação do experimento) foi considerado por outros autores para a análise dos resultados do teste de germinação em sementes de araucária (MOREIRA-SOUZA e CARDOSO, 2003). O critério para avaliação de plântulas normais foi adotado conforme prescrito nas RAS (BRASIL, 2009).

$\mathrm{O}$ teste de envelhecimento acelerado foi realizado conforme metodologia testada preliminarmente, utilizando-se quatro repetições de 25 sementes/tratamento, mantidas por cinco dias em câmara germinativa com controle de umidade relativa e temperatura de $40^{\circ} \mathrm{C}$. Posteriormente, procedeu-se o teste de germinação como descrito anteriormente e calculou-se o índice de velocidade de germinação (IVG), realizado a partir da contagem diária de plântulas normais (MAGUIRE, 1962).

$\mathrm{O}$ teste de condutividade elétrica foi realizado com quatro repetições de 10 embriões intactos/tratamento, acondicionados em recipiente contendo $75 \mathrm{~mL}$ de água ultrapura, conforme descrito por Medeiros e Abreu (2007), com adaptação na temperatura de incubação, optandose por utilizar temperatura de $20^{\circ} \mathrm{C}$, e buscando-se avaliar diferentes tempos de incubação, sendo 0,2 , $4,6,8,10,12$ e 24 horas, o que não foi realizado pelos autores citados, a fim de verificar a taxa de lixiviação e identificar o período de embebição mais adequado à comparação entre as amostras dos tratamentos testados. Os valores de condutividade obtidos em $\mu \mathrm{s} / \mathrm{cm}$ foram corrigidos pela massa das sementes de cada repetição e os resultados expressos em $\mu \mathrm{s} / \mathrm{cm} / \mathrm{g}$.

O teste de tetrazólio é indicado nas RAS (BRASIL, 2009) para avaliação de sementes de araucária, devido ao elevado período de 
permanência das sementes em teste de germinação. Optou-se, a partir de testes preliminares, pela adoção de metodologia alternativa à indicada nas RAS (BRASIL, 2009), proposta por Oliveira et al. (2009), na qual o tempo total para início da avaliação do teste é reduzido.

$\mathrm{O}$ experimento foi realizado em delineamento inteiramente casualizado, em parcelas subdivididas no tempo, em três condições de armazenamento (ambiente, refrigerador e freezer) e quatro períodos de armazenamento (zero, 60, 120 e 180 dias). Os dados obtidos em percentagem foram transformados em arco seno $\sqrt{ } \%$. Realizaramse análise de regressão e de variância com teste de Tukey para separação de médias, a $5 \%$ de probabilidade, através do programa estatístico SAS (2003).

\section{RESULTADOS E DISCUSSÃO}

O grau de umidade apresentado pelas sementes de araucária recém-colhidas foi de $45 \%$ e aumentou até os 60 dias de armazenamento (48\% e $49 \%$ para as sementes armazenadas em freezer e em refrigerador/ambiente, respectivamente), pois a presença das embalagens plásticas permitiu um microambiente mais úmido para as sementes em função da manutenção da taxa respiratória, mesmo quando a condição de armazenamento apresentou baixa umidade relativa do ar. A partir de 60 dias, a umidade aumentou significativamente apenas para as amostras armazenadas em freezer (51\%), condição que manteve elevada umidade relativa com o passar do período de armazenamento. Diferenças mais acentuadas ocorreram apenas a partir dos 120 dias para todas as condições de armazenamento, sendo que ocorreu acréscimo significativo de $4 \%$ na umidade somente para as amostras armazenadas em ambiente natural de laboratório (Figura 1). Considerando-se o intervalo de tempo entre zero e 180 dias de armazenamento, constatou-se uma tendência de acréscimo no grau de umidade apenas para as amostras mantidas em ambiente, possivelmente devido à atividade respiratória associada à manutenção do metabolismo acelerado das sementes em função da elevada amplitude térmica.

Ao se compararem as condições de armazenamento, verificou-se que aos 180 dias houve diferenças mais acentuadas no grau de umidade, com maior teor nas amostras armazenadas

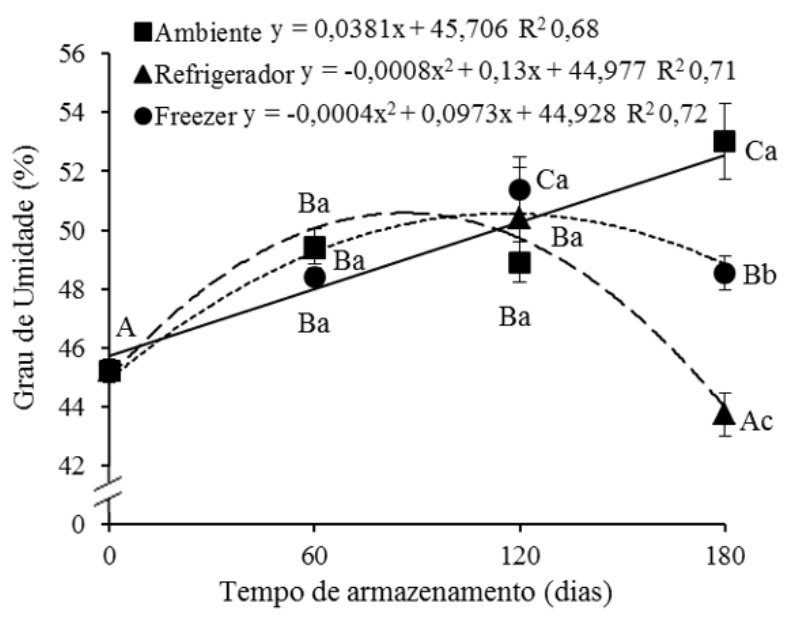

FIGURA 1: Grau de umidade de sementes de Arancaria angustifolia durante 180 dias de armazenamento em ambiente natural de laboratório (sem controle térmico), refrigerador $\left(5^{\circ} \mathrm{C}\right)$ e freezer $\left(-18^{\circ} \mathrm{C}\right)$. As letras referem-se ao teste de Tukey $(\mathrm{P}<0,05)$, maiúsculas - comparação entre tempos de armazenamento; minúsculas comparação entre condições de armazenamento.

FIGURE 1: Moisture content of Araucaria angustifolia seeds during 180 days of storage in natural ambience of laboratory (without thermal control), refrigerator $\left(5^{\circ} \mathrm{C}\right)$ and freezer $(-18$ $\left.{ }^{\circ} \mathrm{C}\right)$. The letters refer to Tukey's test $(\mathrm{P}<0,05)$, uppercase - comparison between storage periods; lowercase - comparison between storage conditions.

em ambiente (53\%), em comparação àquelas armazenadas em freezer (49\%) e em refrigerador (44\%). As alterações no teor de água das sementes divergiram das observados por Piriz Carrillo et al. (2003), pois a umidade das sementes armazenadas em câmara refrigerada a $4^{\circ} \mathrm{C}$ se manteve em torno de $45 \%$ até os 180 dias de armazenamento, independente da embalagem utilizada (polietileno ou etilvinilacetato). Tais autores mantiveram as sementes em câmara refrigerada a $4^{\circ} \mathrm{C}$, por 24 horas, fora das embalagens antes do início do experimento, fato que parece ter colaborado para uma maior uniformidade na umidade das sementes durante o período de armazenamento.

No caso das sementes recalcitrantes, é 
importante relacionar as variações de umidade com o percentual de germinação e vigor, visando observar as alterações fisiológicas decorrentes das condições de armazenamento. Desta forma, observou-se $90 \%$ de germinação das sementes recém-colhidas de araucária aos 70 dias após o inicio do teste de germinação (Tabela 1), as quais apresentaram $45 \%$ de umidade. Ao longo do armazenamento, independente da condição, os teores de água das sementes não interferiram na sua viabilidade, uma vez que foram acima daqueles considerados críticos para a espécie, pois, segundo alguns autores, a viabilidade das sementes de araucária não é afetada até valores mínimos de $36 \%$ (BIANCHETTI e RAMOS, 1981) ou $37 \%$ de umidade (TOMPSETT, 1984).

Conforme a Tabela 1, observou-se que a velocidade de germinação das sementes de araucária foi lenta. Considerando os tempos de avaliação de $0,14,28,42,56$ e 70 dias após a instalação do experimento, verificou-se que o início do estabelecimento de plântulas normais para a maior parte das amostras ocorreu somente em torno do $28^{\circ}$ dia, atingindo o máximo percentual germinativo após 70 dias e, em geral, para sementes que foram previamente submetidas ao envelhecimento artificial, houve atraso no estabelecimento de plântulas normais (Tabela 1). Esta germinação lenta é comum para sementes de araucária, tanto em sementes recém-colhidas quanto após 180 dias armazenamento em câmara fria $\left(0\right.$ a $1^{\circ} \mathrm{C}$ e 90 a $95 \%$ de umidade relativa), onde as amostras levaram 38 e 33 dias, respectivamente, para o início do estabelecimento de plântulas normais (CAÇOLA et al., 2006). Tem sido demonstrado que os envoltórios da semente de araucária constituem um impedimento mecânico à expansão e à absorção de água, atrasando o processo de germinação (FERREIRA e HANDRO, 1979) e, além disso, a germinação das sementes é sensível ao

TABELA 1: Germinação (\%) de sementes de Araucaria angustifolia recém-colhidas e durante armazenamento em ambiente sem controle térmico, refrigerador $\left(5^{\circ} \mathrm{C}\right)$ e freezer $\left(-18^{\circ} \mathrm{C}\right)$, antes e após envelhecimento artificial $\left(5\right.$ dias a $\left.40^{\circ} \mathrm{C}\right)$.

TABLE 1: Germination (\%) of Araucaria angustifolia seeds freshly harvested and during storage in ambience without thermal control, refrigerator $\left(5^{\circ} \mathrm{C}\right)$ and freezer $\left(-18^{\circ} \mathrm{C}\right)$ before and after artificial aging $\left(5\right.$ days at $\left.40^{\circ} \mathrm{C}\right)$.

\begin{tabular}{|c|c|c|c|c|c|c|c|c|c|c|c|c|c|c|c|c|}
\hline \multirow{3}{*}{$\begin{array}{l}\text { Tempo de } \\
\text { armazenamento } \\
\text { (dias) }\end{array}$} & \multirow{4}{*}{$\begin{array}{l}\text { Condição de } \\
\text { armazenamento }\end{array}$} & \multicolumn{8}{|c|}{ Germinação (\%) } & \multicolumn{7}{|c|}{$\begin{array}{c}\text { Germinação após envelhecimento } \\
\text { artificial (\%) }\end{array}$} \\
\hline & & \multirow{2}{*}{$\begin{array}{c}\text { SGN } \\
(\%)\end{array}$} & \multicolumn{14}{|c|}{ Tempos de avaliação (dias) } \\
\hline & & & 0 & 14 & 28 & 42 & 56 & \multicolumn{2}{|c|}{$70^{1}$} & 0 & 14 & 28 & 42 & 56 & \multicolumn{2}{|c|}{$70^{2}$} \\
\hline \multirow[t]{2}{*}{0} & & 0 & 0 & 0 & 1 & 39 & 80 & 90 & a & 0 & 0 & 1 & 12 & 42 & 65 & A \\
\hline & Ambiente & 52 & 0 & 0 & 6 & 71 & 71 & 71 & $A a b$ & 0 & 0 & 9 & 28 & 31 & 44 & $\mathrm{Aab}$ \\
\hline \multirow[t]{3}{*}{60} & Refrigerador & 0 & 0 & 0 & 1 & 19 & 39 & 54 & $\mathrm{Ab}$ & 0 & 0 & 0 & 13 & 26 & 41 & $\mathrm{Aab}$ \\
\hline & Freezer & 0 & 0 & 0 & 0 & 0 & 0 & 0 & $\mathrm{Bb}$ & 0 & 0 & 0 & 0 & 0 & 0 & $\mathrm{Bb}$ \\
\hline & Ambiente & 79 & 0 & 0 & 1 & 8 & 22 & 41 & $\mathrm{Bb}$ & 0 & 0 & 0 & 4 & 11 & 22 & $\mathrm{Bb}$ \\
\hline \multirow[t]{3}{*}{120} & Refrigerador & 24 & 0 & 0 & 8 & 20 & 37 & 59 & $\mathrm{Ab}$ & 0 & 0 & 0 & 4 & 13 & 26 & $\mathrm{Abc}$ \\
\hline & Freezer & 0 & 0 & 0 & 0 & 0 & 0 & 0 & $\mathrm{Cb}$ & 0 & 0 & 0 & 0 & 0 & 0 & $\mathrm{Cb}$ \\
\hline & Ambiente & 80 & 0 & 0 & 0 & 0 & 0 & 0 & $\mathrm{Bc}$ & 0 & 0 & 0 & 0 & 0 & 0 & $\mathrm{Bc}$ \\
\hline \multirow[t]{2}{*}{180} & Refrigerador & 30 & 0 & 0 & 15 & 45 & 59 & 64 & $\mathrm{Aab}$ & 0 & 0 & 0 & 0 & 9 & 9 & Ac \\
\hline & Freezer & 0 & 0 & 0 & 0 & 0 & 0 & 0 & $\mathrm{Bb}$ & 0 & 0 & 0 & 0 & 0 & 0 & $\mathrm{Bb}$ \\
\hline
\end{tabular}

Em que: SGN - sementes germinadas naturalmente nas condições de armazenamento em ambiente e refrigerador antes da submissão ao teste padrão de germinação. ${ }^{1} \mathrm{~A}$ análise de regressão para os resultados de germinação permitiu ajuste das equações para as condições de armazenamento: Ambiente $y=-0,5004 x+95,6\left(R^{2}=0,893\right)$; Refrigerador $\mathrm{y}=0,0029 \mathrm{x}^{2}-0,6379 \mathrm{x}+87,975\left(\mathrm{R}^{2}=0,496\right)$; Freezer $\mathrm{y}=0,0063 \mathrm{x}^{2}-1,575 \mathrm{x}+85,5\left(\mathrm{R}^{2}=0,927\right) .{ }^{2} \mathrm{~A}$ análise de regressão para os resultados de germinação após envelhecimento acelerado permitiu ajuste das equações para as condições de armazenamento: Ambiente $\mathrm{y}=-0,3615 \mathrm{x}+65,185\left(\mathrm{R}^{2}=0,793\right)$; Refrigerador $\mathrm{y}=0,0005 \mathrm{x}^{2}-0,3895 \mathrm{x}+64,405$ $\left(\mathrm{R}^{2}=0,785\right)$; Freezer $\mathrm{y}=0,0045 \mathrm{x}^{2}-1,1375 \mathrm{x}+61,75\left(\mathrm{R}^{2}=0,883\right)$. As letras referem-se ao teste de Tukey $(\mathrm{P}<0,05)$, maiúsculas - comparam as condições de armazenamento; minúsculas - comparam o desempenho de cada condição ao longo do tempo de armazenamento. 
substrato, sendo recomendado o uso de solos que possibilitem maior disponibilidade de água e oxigênio, como os arenosos (AQUILA e FERREIRA, 1894).

Considerando-se um período médio de 70 dias para a estabilização da germinação, independente da condição de armazenamento (Tabela 1), este tempo foi utilizado para comparações entre o percentual de germinação das sementes ao longo do armazenamento em estudo através das análises de regressão e variância. A análise de regressão apontou tendência decrescente significativa dos percentuais de germinação de sementes armazenadas em ambiente ao longo do período de armazenamento, adequando-se uma equação linear (Tabela 1). Já para as demais condições de armazenamento adequaram-se equações polinomiais quadráticas, sendo que, em refrigerador, houve uma leve tendência de decréscimo até os 60 dias de armazenamento, tendendo à estabilização entre os períodos de 60 e 180 dias de armazenamento, enquanto que, em freezer, houve queda acentuada da germinação até os 60 dias de armazenamento.

As amostras recém-colhidas apresentaram $90 \%$ de germinação, e não diferiram significativamente das amostras armazenadas por 60 dias na ausência de controle térmico, mas diferiram significativamente das amostras armazenadas em refrigerador e freezer. Entretanto, aos 120 dias de armazenamento, as sementes armazenadas em refrigerador permaneceram com percentual de germinação próximo a 59\%, enquanto um decréscimo de $30 \%$ na germinação foi detectado para as sementes armazenadas em temperatura ambiente (de 71 para 41\%). Aos 180 dias de armazenamento, as amostras armazenadas em refrigerador mantiveram seu percentual de germinação em $64 \%$, não diferindo significativamente das amostras recém-colhidas (Tabela 1).

Ao comparar o efeito das condições térmicas de armazenamento para cada período amostral, constatou-se que as amostras armazenadas em refrigerador apresentaram maior percentual de germinação em relação às demais condições a partir de 120 dias, fato que destaca tal condição como superior na manutenção da viabilidade das sementes de araucária.

$\mathrm{O}$ armazenamento das sementes a $-18^{\circ} \mathrm{C}$ determinou a perda total da viabilidade aos 60 dias de armazenamento, ou seja, o congelamento provocou a morte do embrião (Tabela 1). No entanto, Caçola et al. (2006) observaram que se armazenadas a temperaturas próximas de $0^{\circ} \mathrm{C}$, as sementes de araucária mantêm seu potencial germinativo de $97 \%$ por um período de até 180 dias.

Portanto, observou-se claramente que o armazenamento em refrigerador favoreceu a conservação da viabilidade das sementes até o tempo de 180 dias de armazenamento. Visto que a umidade não foi um fator interferente no processo, constatou-se que a temperatura mais baixa em refrigerador (em média de $5^{\circ} \mathrm{C}$ ) em relação ao ambiente favoreceu a diminuição da atividade metabólica das sementes, o que possivelmente contribuiu substancialmente para a manutenção da viabilidade das amostras por um período de 180 dias. Estes efeitos positivos concordam com outros autores, que observaram baixas taxas respiratórias em sementes de araucária quando armazenadas em temperaturas de 2 e $10^{\circ} \mathrm{C}$ (AMARANTE et al., 2007), ou que observaram que o percentual de germinação de araucária pode ser mantido em $61 \%$ se as sementes forem armazenadas em temperatura de $4^{\circ} \mathrm{C}$ (FOWLER et al., 1998).

Outra evidência de que as sementes de araucária não toleram $\mathrm{o}$ armazenamento por período prolongado quando mantidas em ambiente sem controle térmico é o elevado percentual de germinação (52\%) observado aos 60 dias de armazenamento antes de se iniciar o teste de germinação (Tabela 1), valor que aumentou para percentuais próximos a $80 \%$ aos 120 e 180 dias de armazenamento, enquanto que as amostras armazenadas em refrigerador atingiram percentual máximo de 30\% de germinação antes da submissão ao teste de germinação. Estes resultados demonstram novamente a necessidade de armazenamento das amostras com controle de temperatura.

Ao se realizar o teste de envelhecimento artificial observaram-se reduções na porcentagem e no índice de velocidade de germinação das sementes nas condições de armazenamento em estudo (Tabela 1 e Figura 2B). A redução observada foi de $100 \%$ na germinação das amostras armazenadas no ambiente e em freezer, no entanto, para as amostras na condição de refrigerador, a redução foi de $91 \%$. Este fato indica que as sementes de araucária poderiam permanecer viáveis se armazenadas sob condição de refrigerador, à temperatura de $5^{\circ} \mathrm{C}$, 

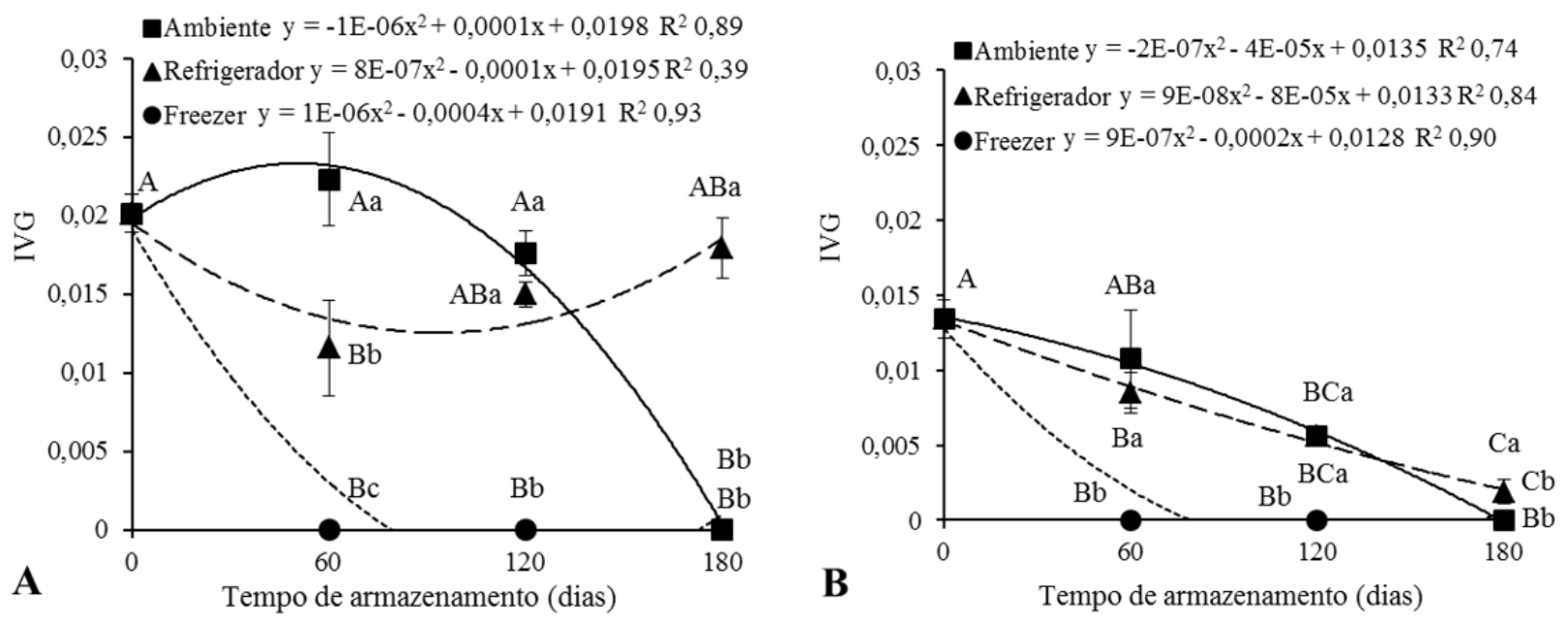

FIGURA 2: Índice de Velocidade de Germinação (IVG) de sementes de Araucaria angustifolia recémcolhidas e durante 180 dias de armazenamento em ambiente natural de laboratório (sem controle térmico), refrigerador $\left(5^{\circ} \mathrm{C}\right)$ e freezer $\left(-18^{\circ} \mathrm{C}\right)$, não envelhecidas $(\mathrm{A})$ e envelhecidas artificialmente (B), ao longo do período de armazenamento. As letras referem-se ao teste de Tukey $(\mathrm{P}<0,05)$, maiúsculas - comparação entre tempos de armazenamento; minúsculas comparação entre condições de armazenamento. ${ }^{*} \mathrm{O}$ valor obtido pelo IVG foi dividido pelo número de sementes por repetição.

FIGURE 2: Germination speed index (IVG) of Araucaria angustifolia seeds freshly harvested and during 180 days of storage in natural ambience of laboratory (without thermal control), refrigerator $\left(5^{\circ} \mathrm{C}\right)$ and freezer $\left(-18{ }^{\circ} \mathrm{C}\right)$, not aged $(\mathrm{A})$ and artificially aged $(\mathrm{B})$ throughout the storage period. The letters refer to Tukey's test $(\mathrm{P}<0,05)$, uppercase - comparison between storage periods; lowercase - comparison between storage conditions. *The value obtained by IVG was divided by the number of seeds per replication.

por período superior a 180 dias.

Além disso, os resultados obtidos sugerem a eficiência do envelhecimento artificial para antecipar os valores de viabilidade das sementes mantidas em condições naturais, uma vez que as sementes submetidas ao envelhecimento artificial imediatamente após a colheita $(65 \%)$ apresentaram viabilidade significativamente similar àquelas envelhecidas naturalmente após 60 dias de armazenamento em refrigerador (54\%) e em ambiente sem controle térmico (71\%) (Tabela $1)$.

Além do envelhecimento artificial, outro importante teste na avaliação do vigor das sementes durante o envelhecimento natural no armazenamento refere-se ao índice de velocidade de germinação, o qual diferiu entre as condições já nos primeiros 60 dias de armazenamento (Figura 2A). O IVG das sementes imediatamente após a colheita foi de 0,02 por semente, não diferindo apenas daquelas sementes armazenadas em ambiente sem controle térmico por 60 dias. Aos 120 dias de armazenamento não houve diferença significativa entre o IVG das sementes armazenadas em refrigerador $(0,018)$ e em ambiente $(0,015)$. Entretanto, com o avanço do período de armazenamento, houve acentuado decréscimo no IVG das sementes armazenadas em ambiente, em contraste com as amostras armazenadas em refrigerador que permaneceram com valores próximos a 0,02 .

As sementes recém-colhidas após o envelhecimento artificial apresentaram um IVG de 0,013 por semente, equivalente ao observado para as sementes não envelhecidas artificialmente, após 120 dias de armazenamento em refrigerador e em ambiente sem controle térmico (Figura 2A e 2B). A análise do IVG das sementes após envelhecimento artificial demonstrou que o vigor destas, sob condições de armazenamento em refrigerador, mesmo com valores baixos, manteve- 

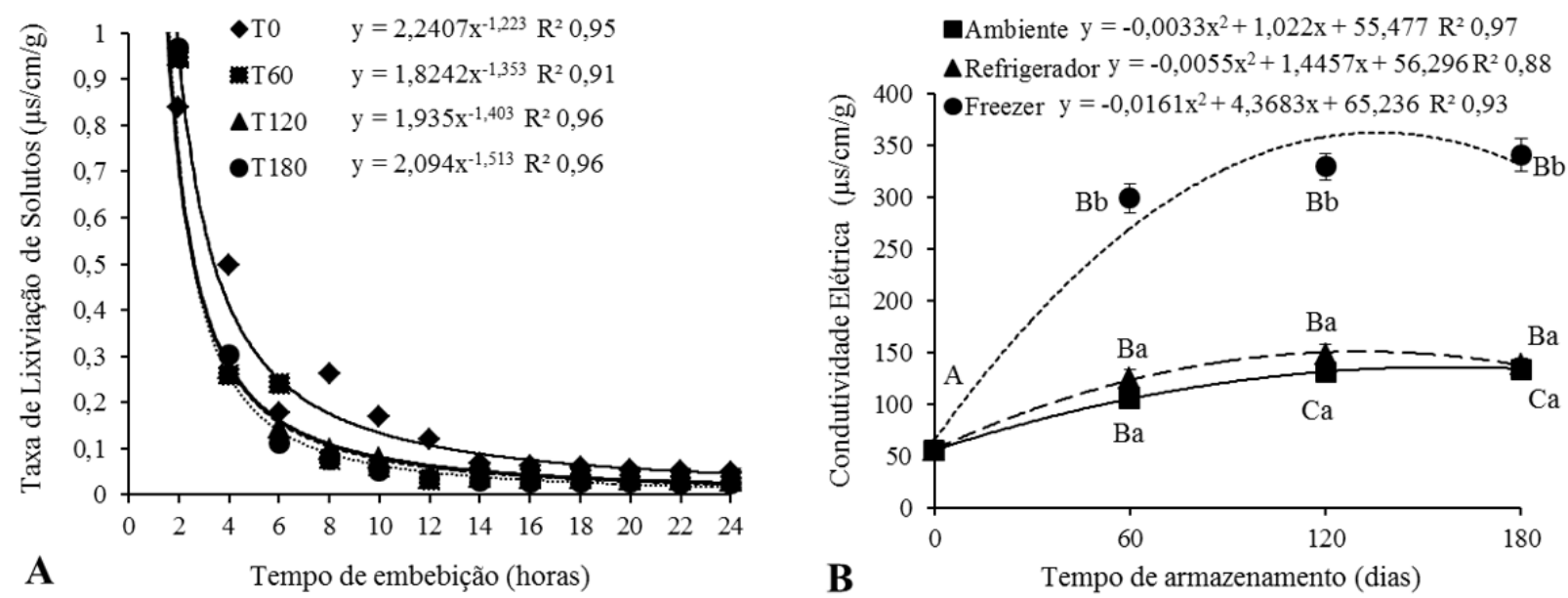

FIGURA 3: Taxa média de lixiviação de solutos com base nas leituras da condutividade elétrica de sementes de Araucaria angustifolia durante 180 dias de armazenamento nas diferentes condições (A); Condutividade elétrica $(\mu \mathrm{S} / \mathrm{cm} / \mathrm{g})$ de sementes de Araucaria angustifolia durante 180 dias de armazenamento em ambiente natural de laboratório (sem controle térmico), refrigerador $\left(5^{\circ} \mathrm{C}\right)$ e freezer $\left(-18^{\circ} \mathrm{C}\right)$, após 12 horas de embebição em água ultrapura $(\mathrm{B})$. As letras referemse ao teste de Tukey $(\mathrm{P}<0,05)$, maiúsculas - comparação entre tempos de armazenamento; minúsculas - comparação entre condições de armazenamento. Onde: T0 - recém-colhidas; T60 - aos 60 dias de armazenamento; T120 - aos 120 dias de armazenamento; T180 - aos 180 dias de armazenamento.

FIGURE 3: Average rate of solutes leaching based on the electrical conductivity of Araucaria angustifolia seeds during 180 days of storage in different conditions (A); Electrical conductivity ( $\mu \mathrm{S} /$ $\mathrm{cm} / \mathrm{g}$ ) of Araucaria angustifolia seeds during 180 days of storage in natural ambience of laboratory (without thermal control), refrigerator $\left(5{ }^{\circ} \mathrm{C}\right)$ and freezer $\left(-18^{\circ} \mathrm{C}\right)$ after 12 hours of imbibitions in ultrapure water. The letters refer to Tukey's test $(\mathrm{P}<0,05)$, uppercase comparison between storage periods; lowercase - comparison between storage conditions. Where: T0 - freshly harvested; T60 - 60 days of storage; T120 - 120 days of storage; T180 -180 days of storage.

se superior $(\mathrm{P}<0,05)$ às amostras armazenadas no ambiente sem controle térmico, sugerindo que as sementes armazenadas em refrigerador se mantiveram mais vigorosas ao longo dos 180 dias de armazenamento. Este resultado é importante, pois se refere à capacidade de estabelecimento das sementes em condições de campo (FONTES et al., 2001).

$\mathrm{O}$ teste de condutividade elétrica foi utilizado para corroborar as demais análises de vigor das sementes durante o armazenamento, uma vez que o início do processo de deterioração é caracterizado pela desestruturação do sistema de membranas celulares (SANTOS et al., 2005). A condutividade elétrica foi monitorada a cada 2 horas até um tempo final de 24 horas (Figura $3 \mathrm{~A})$. O tempo de 12 horas de embebição promoveu a menor taxa de lixiviação de solutos, ou seja, houve estabilização na condutividade, permitindo a comparação entre todas as condições de armazenamento.

Com o decorrer do tempo de armazenamento, observou-se um aumento na lixiviação de solutos, sendo que, particularmente para as amostras armazenadas no freezer, a lixiviação foi superior, chegando ao valor de $341 \mu \mathrm{s} / \mathrm{cm} / \mathrm{g}$ aos 180 dias de armazenamento (Figura 3B). Já as sementes armazenadas em refrigerador e ambiente mantiveram-se muito semelhantes até o tempo de 180 dias. Desta forma, o teste de condutividade elétrica não foi sensível para detectar diferenças de vigor entre as sementes armazenadas em ambiente e em refrigerador aos 60, 120 e 180 após a colheita. Assim, a aplicação do teste de condutividade elétrica para sementes de araucária pode ser indicada para detectar graus baixos ou elevados de deterioração, sendo menos sensível para detectar graus intermediários de 


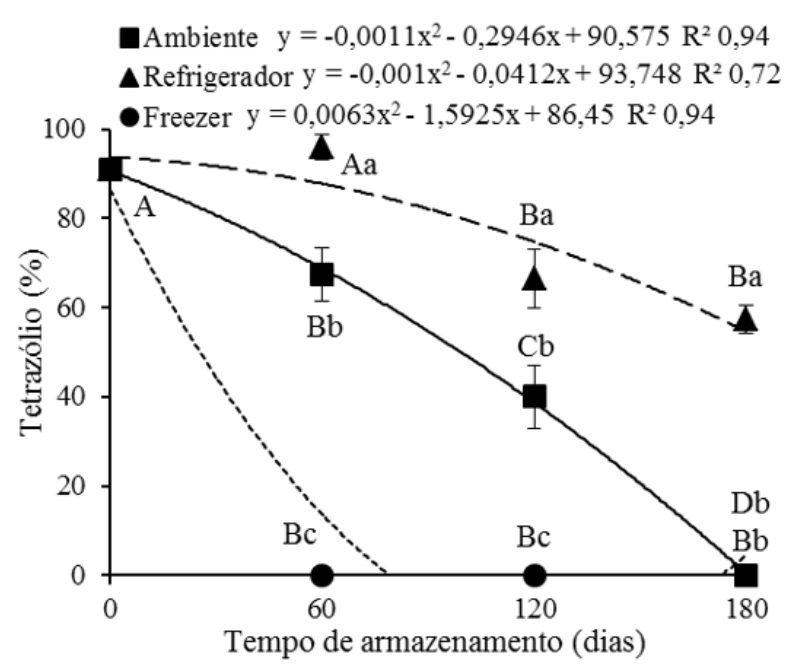

FIGURA 4: Percentual de sementes viáveis de Araucaria angustifolia no teste de tetrazólio durante 180 dias de armazenamento em ambiente natural de laboratório (sem controle térmico), refrigerador $\left(5^{\circ} \mathrm{C}\right)$ e freezer $\left(-18^{\circ} \mathrm{C}\right)$. As letras referem-se ao teste de Tukey ( $\mathrm{P}<0,05)$, maiúsculas - comparação entre tempos de armazenamento; minúsculas - comparação entre condições de armazenamento.

FIGURE 4: Percentage of viable seeds of Araucaria angustifolia in the tetrazolium test during 180 days of storage in natural ambient of laboratory (without thermal control), refrigerator $\left(5{ }^{\circ} \mathrm{C}\right)$ and freezer $(-18$ $\left.{ }^{\circ} \mathrm{C}\right)$. The letters refer to Tukey's test $(\mathrm{P}<0,05)$, uppercase - comparison between storage periods; lowercase - comparison between storage conditions.

deterioração.

O teste de tetrazólio, método alternativo sugerido pelas RAS (BRASIL, 2009) para análise da viabilidade das sementes de araucária, já foi utilizado com sucesso por outros autores na avaliação da viabilidade de sementes de araucária (SOROL e PÉREZ, 2001; MEDEIROS e ABREU, 2007; OLIVEIRA et al., 2009). Neste trabalho, o teste de tetrazólio demonstrou que $\mathrm{o}$ armazenamento em refrigerador foi superior na manutenção da viabilidade das sementes ao longo do período de armazenamento em relação às demais condições (Figura 4).
Aos 180 dias de armazenamento, as sementes conservadas em refrigerador apresentaram 57\% de viabilidade, enquanto aquelas em ausência de controle térmico e em freezer apresentaram perda total de viabilidade.

O resultado de viabilidade pelo teste de tetrazólio apresentou correlação positiva com os resultados obtidos pelo teste de germinação, sendo mais sensível na detecção das diferenças de viabilidade, pois as sementes armazenadas em refrigerador apresentaram viabilidade significativamente diferente em relação às demais condições em todos os tempos de armazenamento.

\section{CONCLUSÕES}

As sementes de araucária apresentaram menor redução na viabilidade e vigor, mantendo $64 \%$ de germinação aos 180 dias após a colheita, quando armazenadas sob temperatura próxima a $5^{\circ} \mathrm{C}$, na condição de armazenamento em refrigerador.

A umidade das sementes de araucária foi mantida em níveis superiores aos considerados críticos para araucária nas condições de armazenamento estudadas até o tempo de 180 dias de armazenamento, o que permite concluir que a umidade não foi um fator preponderante à perda de vigor e viabilidade das sementes.

\section{AGRADECIMENTOS}

Os autores agradecem à CAPES pela bolsa de mestrado concedida ao primeiro autor e ao $\mathrm{CNPq}$ pela bolsa de produtividade em pesquisa concedida ao segundo autor.

\section{REFERÊNCIAS BIBLIOGRÁFICAS}

AMARANTE, C. V. T. et al. Conservação pós-colheita de pinhões [sementes de Araucaria angustifolia (Bertoloni) Otto Kuntze] a rmazenados em diferentes temperaturas. Ciência Rural, Santa Maria, v. 37, n. 2, p. 346-351, mar./abr. 2007.

AQUILA, M. E. A.; FERREIRA, A. G. Germinação de sementes escarificadas de Araucaria angustifolia em solo. Ciência e Cultura, v. 36, p. 1583-1589, 1984.

BIANCHETTI, A.; RAMOS, A. Efeito da temperatura de secagem sobre o poder germinativo 
de sementes de Araucaria angustifolia (Bert.) O. Ktze. Boletim de Pesquisa Florestal, Curitiba, n. 2, p. 27- 56, jun. 1981.

BRASIL. Ministério do Meio Ambiente. Instrução Normativa N. 6, de 26 de setembro de 2008. Lista Oficial das Espécies da Flora Brasileira Ameaçadas de Extinção, 2008. Disponível em: $<$ (http://portal.saude.gov.br/portal/arquivos/pdf/ instrucao6.pdf)> Acesso em: 14 de maio de 2011.

BRASIL. Ministério da Agricultura, Pecuária e Abastecimento. Regras para análise de sementes. Brasília: MAPA/ACS, 2009. $399 \mathrm{p}$.

CAÇOLA, Á. V. et al. Qualidade fisiológica de sementes de Araucaria angustifolia (Bertol.) Kuntze submetidas a diferentes condições de armazenamento e a escarificação. Ciência Florestal, Santa Maria, v. 16, n. 4, p. 391398, out./dez. 2006.

EIRA, M. T. S. et al. Efeito do teor de água sobre a germinação de sementes de Araucaria angustifolia (bert.) O. Ktze. Revista Brasileira de Sementes, v. 16, n. 1, p. 71-75, 1994.

EPAGRI/CIRAM. Atlas climatológico do estado de Santa Catarina. Disponível em: <(http://www. ciram.epagri.rct-sc.br) $>$ Acesso em: 20 de junho de 2011.

FARJON, A. 2006. Araucaria angustifolia. In: IUCN - International Union for Conservation of Nature and Natural Resources, 2011. IUCN red list of threatened species. Disponível em: $<$ (http:// www.iucnredlist.org/apps/redlist/details/32975/0)> Acesso em: 4 de junho de 2011.

FERREIRA, A. G. Aspectos estructurales de las semillas de Araucaria angustifolia (Bert.) O. Ktze. Iheringia. Série Botânica, v. 26, p. 3-7, 1981.

FERREIRA, A. G.; HANDRO, W. Aspects of seed germination in Araucaria angustifolia (Bert.) O. Ktze. Revista Brasileira de Botânica, v. 2, p. 7-13, 1979.

FONTES, B. P. D.; DAVIDE, L. C.; DAVIDE, A. C. Fisiologia e citogenética de sementes envelhecidas de Araucaria angustifolia. Ciência e Agrotecnologia, Lavras, v. 25, n. 2, p. 346-355, mar./abr. 2001.

FOWLER, J. A. P.; BIANCHETTI, A.; ZANON, A. Conservação de sementes de pinheirodo-paraná sob diferentes condições de ambientes e embalagens. Colombo: EMBRAPA/ CNPF, 1998. p.1-4. (Comunicado Técnico, n. 34).

LORENZI. H. Árvores brasileiras: manual de identificação e cultivo de plantas arbóreas nativas do Brasil. 4. ed. Nova Odessa: Plantarum, 2002. v. 1. $368 \mathrm{p}$.

MAGUIRE, J. D. Speed of germination-aid in selection and evaluation for seedling emergence and vigour. Crop Science, Madson, v. 2, n. 1, p. 176-177, 1962.

MEDEIROS, A. C. S.; ABREU, D. C. A. Desidratação ultra-rápida de embriões. Pesquisa Florestal Brasileira, n. 54, p. 119-125, 2007.

MOREIRA-SOUZA, M.; CARDOSO, E. J. B. N. Practical method for germination of Araucaria angustifolia (Bert.) O. Ktze. Seeds. Scientia Agricola, v. 60, n. 2, p. 389-391, abr./jun. 2003.

OLIVEIRA, L. M. et al. Tetrazolium test in Araucaria angustifolia seeds. In: CONGRESSO FLORESTAL MUNDIAL, 13., 2009, Buenos Aires. Anais... Buenos Aires, 2009.

PIRIZ CARRILLO, V. et al. Refrigerated storage of seeds of Araucaria angustifolia (Bert.) O. Kuntze over a period of 24 months. Seed Science and Technology, v. 31, n. 2, p.411-421, 2003.

RAMOS, A.; BIANCHETTI, A. Metodologia para determinação do teor de umidade de sementes de Araucaria angustifolia (Bert.) O. Ktze. Revista Brasileira de Sementes, v. 12, n. 3, p. 9-16, 1990.

RAMOS, A.; CARNEIRO, J. G. A. Alterações fisiológicas em sementes de Araucaria angustifolia (Bert.) O. Ktze. armazenadas após secagem em estufa. In: CONGRESSO FLORESTAL DO PARANÁ, 1988, Curitiba. Anais... Curitiba, 1988. p. 628-643.

RAMOS, A.; CARNEIRO, J. G. A. Envelhecimento artificial de sementes do pinheiro do Paraná. Pesquisa Agropecuária Brasileira, Brasília, n. 26, p. 19-24, jan. 1991.

SANTOS, C. R.; MENEZES, N. L.; VILLELA, F. A. Modificações fisiológicas e bioquímicas em sementes de feijão no armazenamento. Revista Brasileira de Sementes, v. 27, n. 1, p.104-114, 2005.

SAS. SAS Institute Inc ${ }^{\circledR}$ 2003. Cary, NC, USA, Lic. UDESC: SAS Institute Inc, 2003.

SOROL, C. B.; PEREZ, M. A. Determinacion de la viabilidad de las semillas de araucaria (Araucaria angustifólia Bert. O. Ktze.) através de la 
prueba topográfica por tetrazolio. In: TOMPSETT, P. B. Desiccation studies in relation to CONGRESSO BRASILEIRO DE SEMENTES, the storage of Araucaria seed. Annals of Applied 2001, Curitiba. Anais... Informativo ABRATES: Botany, Webesbourne, v. 105, n. 3, p. 581-586, Curitiba, v. 11, n. 2, p. 287, 2001. 1984. 